\title{
Analyse von zirkulären RNAs mithilfe der rolling circle amplification
}

MARCEL BOSS, CHRISTOPH ARENZ

INSTITUT FÜR CHEMIE, HU BERLIN

\section{Circular RNA (circRNA) represents a group of long non-coding RNAs} with specific biological functions. The investigation of this class of RNAs is very challenging as they are often poorly expressed and in the simultaneous presence of their linear counterparts. Rolling circle amplification (RCA) has been little used so far for this application, but it makes ideal use of the specific properties of circRNAs. Moreover, it can be combined with all other common PCR methods.

DOI: $10.1007 / \mathrm{s} 12268-020-1451-\mathrm{x}$

(C) Die Autoren 2020

Die Frage nach den Mechanismen der Genregulation gehört seit jeher zu den grundlegendsten Fragen der Zellbiologie. Spätestens mit dem Abschluss des humanen Genomprojekts im Jahr 2003 stellte sie sich mit besonderer Dringlichkeit: Wie war es möglich, dass der Mensch und der vermeintlich wenig komplexe Fadenwurm Caeonorhabditis elegans in etwa die gleiche Anzahl an Genen aufweisen konnten? Die Antwort auf diese Frage musste in der Regulation der ein- zelnen Gene liegen. Mit Entdeckung der microRNAs schien auch ein Mechanismus gefunden, der die Komplexität aufwies, um eine so umfangreiche und fein abgestimmte Regulation der Gene zu ermöglichen. Nach den microRNAs und verwandten, kurzen regulatorischen RNAs rückten lange nichtcodierende RNAs (IncRNA oder lincRNA) als regulatorische RNAs ins Blickfeld. Spätestens die Entdeckung der zirkulären RNAs (circRNAs) zeigte, dass die Feinregulation der Gene weit umfangreicher war, als bis dahin angenommen.

\section{CDR1as und die mikroRNA miR-7}

Die Charakterisierung der zirkulären RNA CDR1as zeigte am Beispiel der microRNA miR-7, dass microRNAs selbst einem komplexen feinregulatorischen Mechanismus durch circRNAs unterliegt können [1]. Es konnte gezeigt werden, dass CDR1as mehr als 70 Bindestellen für miR-7 aufweist, ohne selbst einer microRNA-induzierten Degradation zu unterliegen. Damit stellt die CDR1as eine Plattform dar, die einen direkten Einfluss auf die zelluläre Konzentration der miR-7 hat.

Ein zentraler Punkt zum Verständnis der circRNA-vermittelten Regulation ist die Halbwertszeit von circRNA. Aufgrund des Nichtvorhandenseins eines 3'- oder 5'-Terminus findet kein Abbau durch Exonukleasen statt, was eine drastisch erhöhte biologische Stabilität zur Folge hat. So weisen microRNAs eine durchschnittliche Halbwertszeit von etwa 20 Minuten auf, wohingegen ausgewählte circRNAs selbst nach 24 Stunden detektier-
A<smiles>c1ccccc1</smiles>
circRNA
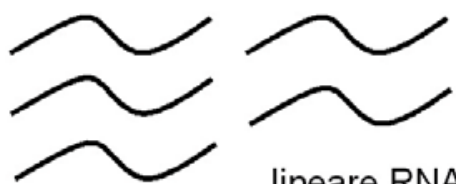

lineare RNA

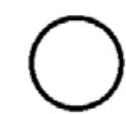
circRNA
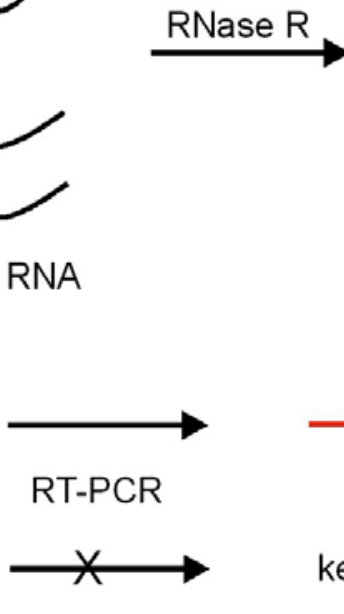

keine cDNA

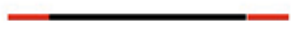

cDNA

B<smiles>[C+]1C=CC=CCC=C1</smiles>

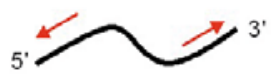

4 Abb. 1: Analyse von zirkulärer RNA unter Zuhilfenahme von RNase R. A, Aus zellulärer RNA lassen sich circRNAs anreichern. Es werden jedoch einzelne circRNAs ungewollt abgebaut. Ebenso verbleibt lineare RNA in der Analyse. B, Eine zusätzliche Selektivität für circRNA kann bei der Amplifizierung durch reverse Transkription/PCR (RT-PCR) durch ein geeignetes Primerdesign erreicht werden. 


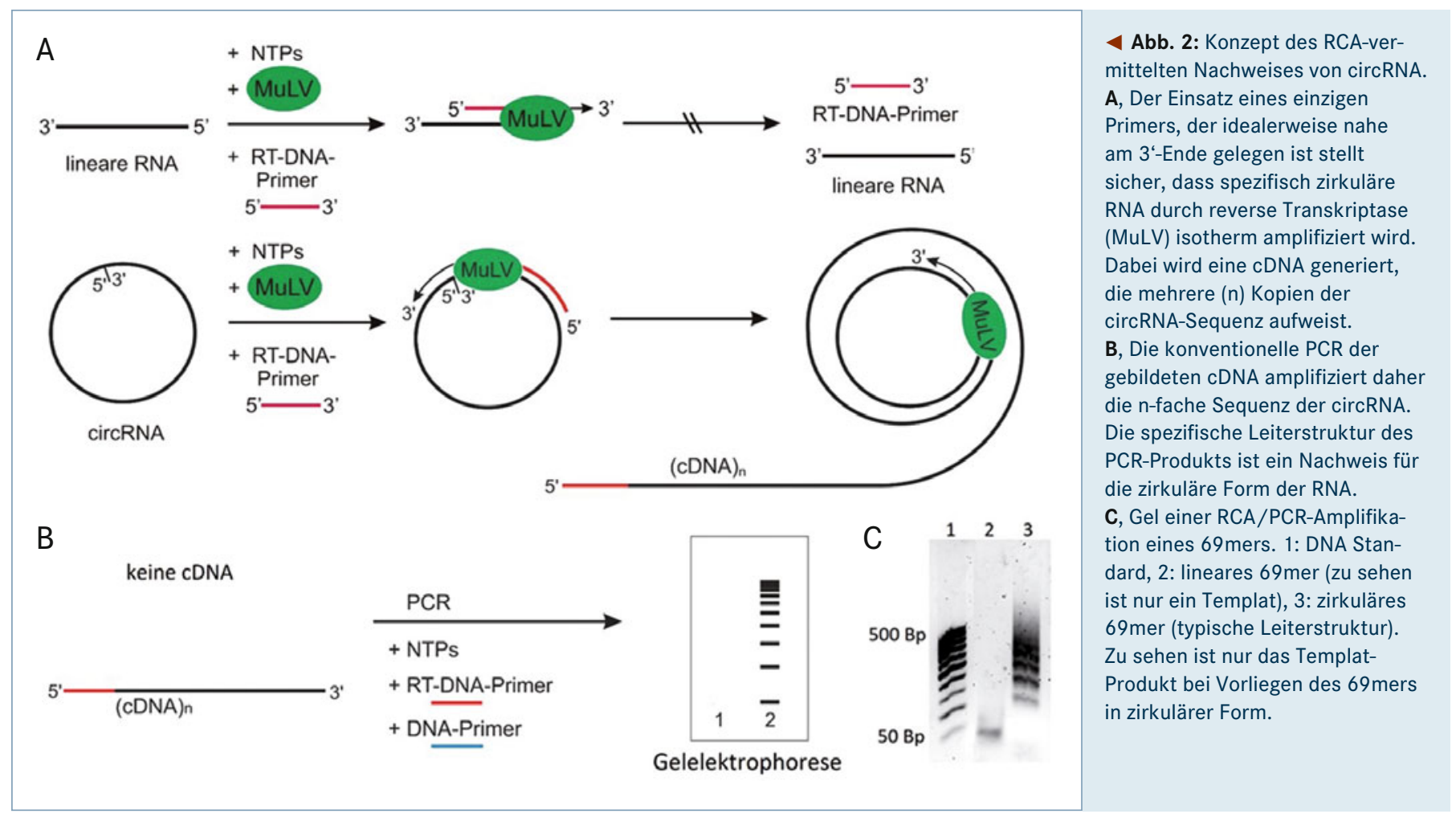

bar sind. Diese Tatsache lässt den Schluss zu, dass circRNAs nicht nur über ihre Konzentration (bzw. das Ausmaß ihrer Transkription) regulieren, sondern auch über ihre deutlich längere Halbwertszeit.

\section{Herausforderungen der circRNA- Analyse}

Die Erforschung der zirkulären RNA hat nach der Charakterisierung der circRNA CDR1as rasch große Beachtung erlangt. Dabei konnte schnell festgestellt werden, dass die experimentelle Untersuchung von circRNAs keine leichte Aufgabe ist [2]. Zu vielen circRNAs gibt es auch ein lineares Gegenstück, sodass der einzige Unterschied in der Verknüpfung des 3'- und 5'-Terminus besteht. Dies in Kombination mit der Tatsache, dass die meisten circRNAs nur gering exprimiert vorliegen, führt zu großen Herausforderungen in der Erforschung zirkulärer RNA. Eine der gängigsten Methoden zur Untersuchung von circRNAs besteht im Gebrauch von RNase $\mathrm{R}^{+}$-Bibliotheken. Dabei wird die gesamte RNA aus Zellen isoliert und anschließend mit der Exonuklease R behandelt. Dieses Enzym baut lineare RNA beginnend vom 3‘-Terminus ab, während zirkuläre RNA von dem Abbau nicht betroffen sein sollte. Dieses Verfahren wird in der Tat eingesetzt, um die Adressierung von linearen RNAs gleicher Sequenz zu vermeiden und somit falsch positive Ergebnisse zu verhindern. In der
Realität ist der selektive und vollständige Abbau von linearer RNA aber schwer umsetzbar. Einerseits kann nicht sichergestellt werden, dass die gesamte lineare RNA abgebaut wurde und andererseits besitzen auch viele circRNAs keine absolute RNase-R-Stabilität. Daraus ergeben sich große Herausforderungen für experimentelle Methoden zur Untersuchung zirkulärer RNA.

\section{RT-qPCR als Standardmethode für circRNA-Identifizierung}

Eine etablierte Methode für die Identifizierung zirkulärer RNA ist die reverse Transkription mit anschließender quantitativer PCR $[3,4]$. Diese RT-qPCR wird mit RNase R ${ }^{+}$-Bibliotheken und divergenten DNA-Primern durchgeführt. Die Primer sind so entworfen, dass in Richtung 3‘, $5^{\prime}$-Verknüpfung der circRNA revers transkribiert und so die entsprechende cDNA generiert wird. So sollte selbst bei nicht vollständigem RNase-R-vermittelten Abbau keine lineare RNA amplifiziert werden. Die anschließende qPCR mit dem zweiten DNA-Primer ermöglicht das Amplifizieren der cDNA. Dieses Verfahren dient zum spezifischen Nachweis von circRNAs aus einer total-RNA-Präparation aus Zelllinien [5]. Diese Methode findet auch Anwendung bei der Bestätigung von bioinformatischen Analysen [6]. Allerdings bestehen bei der experimentellen Untersuchung zirkulärer RNA mit der RT-qPCR auch einige Her- ausforderungen. circRNAs mit niedriger RNase-R-Resistenz fallen leicht durchs Suchraster, da sie beim RNase-R-Abbau der Bibliothek auch selbst zerstört werden und ein falsch negatives Ergebnis generieren. Andererseits bietet auch das Primerdesign hin zur Zyklisierungsstelle keinen absoluten Schutz gegen falsch positive Resultate, da die reverse Trankriptase unter Umständen eine Verbrückung der beiden Enden von linearer RNA bewirken kann. Aus diesem Grund werden stetig neue Methoden zur Untersuchung von zirkulärer RNA etabliert.

\section{RT-qPCR über einen rolling circle- Mechanismus}

Ein neu entwickelter Ansatz zum spezifischen Nachweis von zirkulärer RNA ist eine RT-qPCR über einen rolling circle-Mechanismus [7]. Dabei werden für die reverse Transkription ein Primer und eine reverse Trankriptase verwendet, die die zirkuläre RNA über einen rolling circle-Mechanismus amplifizieren (Abb. 2A). Die dabei gebildete cDNA enthält eine sich wiederholende komplementäre Sequenz der circRNA. Es wird also eine multimere cDNA gebildet. AnschlieBend wird eine PCR zu Amplifikation dieser cDNA durchgeführt. Aufgrund der multimeren Sequenz ergeben sich mehrere Bindestellen für den DNA-Primer (Abb. 2B). Somit können unterschiedlich lange DNA-Fragmente amplifiziert werden. Diese Tatsache 


\section{A}

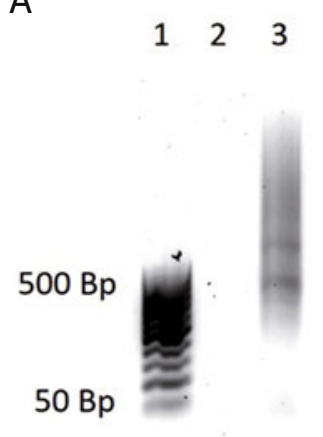

B

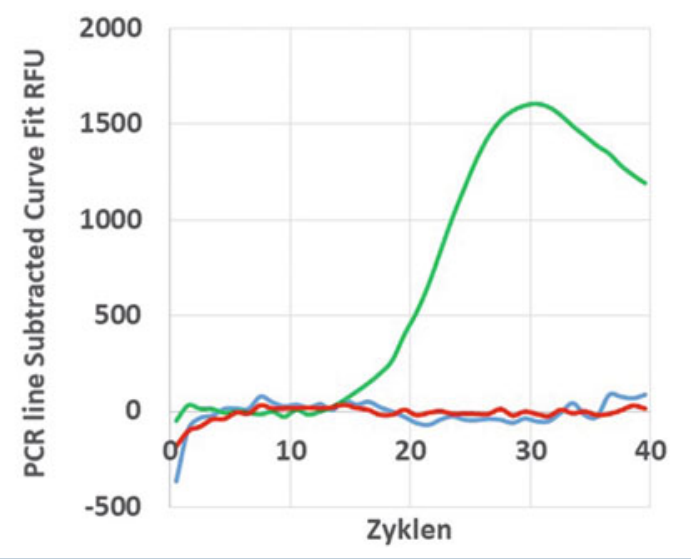

Abb. 3: Amplifikation der circRNA CRKL (466 Nukleotide). A, Gelmethode. 1: DNA Standard, 2: lineares CRKL, 3: zirkuläres CRKL. B, Kombination mit qPCR. Gezeigt ist die Fluoreszenz als Indikator für die DNA-Synthese in Abwesenheit von Templat (blaue Linie) oder in Anwesenheit von linearer (rote Linie) oder zirkulärer CRKL (grüne Linie).

ermöglicht die Durchführung der Methode in zwei verschiedenen Ausführungen. In der ersten Variante kann nach erfolgter rolling circle amplification (RCA) eine normale PCR durchgeführt werden und die gebildeten
DNA-Fragmente werden über eine Gelelektrophorese visualisiert. Dabei wird eine Art Leiterstruktur der DNA-Banden nachgewiesen (Abb. 2C). Nach unserer Ansicht ist dieses Experiment, das ohne jegliche RNase-R-
Behandlung und ohne moderne Instrumentierung auskommt, ein extrem robuster, qualitativer Nachweis für das Vorliegen einer circRNA. Die Möglichkeit, auch mit einer normalen PCR zu einem eindeutigen Signal für zirkuläre RNA zu kommen, macht diese Methode ideal sowohl für kleine als auch große Labore. Alternativ kann nach der RCA eine standardisierte qPCR durchgeführt werden, um das Signal zu amplifizieren. Die qPCR hat das Potenzial für HochdurchsatzScreenings im großen Forschungsmaßstab. Da die RCA Reaktion jedoch eine schwer vorhersehbare Amplifikation der circRNA bewirkt, muss für eine Quantifizierung ein geeigneter zirkulärer Standard hinzugezogen werden. In Kombination mit qPCR ist selbst die RCA nicht absolut spezifisch für circRNA. In unseren Händen zeigte die RCA in Kombination mit qPCR ohne den Einsatz von RNase $\mathrm{R}$ jedoch stets mindestens eine 1.000fache Selektivität. So ergaben im ungünstigsten Fall 250 fmol lineare RNA eine nur leicht schwächere Amplifikation als 250 amol circRNA [7]. Eine absolute Spezi-

\section{Hier steht eine Anzeige.}


fität wird auch hier nur unter Nutzung von RNase $\mathrm{R}$ beobachtet. Allerdings ist gerade die Möglichkeit, sie mit jeder anderen Methode zu kombinieren, die besondere Stärke der RCA.

\section{Anwendung in der Erforschung genregulatorischer Fehlfunktionen}

Da zirkuläre RNAs umfangreiche Funktionen im Bereich der Genregulation aufweisen, besteht ein enger Zusammenhang mit verschiedenen Krankheiten. Beispielsweise haben Studien gezeigt, dass die Expression der circRNA CDR1as durch eine Überexpression von Prion-Proteinen in Zellen eingeleitet wird [8]. Eine Regulation dieser Art deutet auf einen Zusammenhang zwischen CDR1as und Prionenkrankheiten hin. Ein weiteres Beispiel ist der Splicingfaktor MBL, der die Splicing-Effizienz der prä-mRNA und der circRNA circMBL reguliert und eng mit der mytonischen Dystrophie verknüpft ist [9]. Da die circRNA circMBL durch Bindung des Splicingfaktor MBL direkten Einfluss auf diesen nehmen kann, scheint auch ein Zusammenhang zwischen circRNA-Expressionslevel und der mytonischen Dystrophie zu bestehen.

Diese Beispiele zeigen, dass die Expressionslevel zirkulärer RNAs von entscheidender Bedeutung bei unterschiedlichsten Erkrankungen sind. Daher sind Methoden wie die RT-qPCR zur Bestimmung der Expressionslevel von entscheidender Bedeutung für die Erkennung von Krankheiten und unerlässlich für die medizinische Forschung.

\section{Literatur}

[1] Hansen TB, Jensen TI, Clausen BH et al. (2013) Natural RNA circles function as efficient microRNA sponges. Nature 495:384-388

[2] Szabo L, Salzman J (2016) Detecting circular RNAs: bioinformatic and experimental challenges. Nat Rev Gen 17:679-692

[3] Jeck WR, Sorrentno JA, Wang K et al. (2013) Circular RNAs are abundant, conserved and associated with ALU repeats. RNA 19:141-157

[4] Zhang XO, Wang HB, Zhang Y et al. (2014) Complementary sequence-mediated exon circularization. Cell 159:134-147

[5] Legnini I, Timoteo LD, Rossi F et al. (2017) Circ-ZNF609 is a circular RNA that can be translated and functions in myogenesis. Mol Cell 66:22-37

[6] Hansen TB, Veno MT, Damgaard CK, Kjems J (2015) Comparison of circular RNA prediction tools. Nucleic Acids Res 44:e58

[7] Boss M, Arenz C (2020) A fast and easy method for specific detection of circRNA by rolling circle amplifikation. ChemBioChem 21:793-796

[8] Saroh J, Yamamura T (2004) Gene expression profile following stable expression of the circular prion protein. Cell Mol Neurobiol 24:793-814

[9] Ashwal-Fluss R, Meyer M, Pamudurti NR et al. (2014) circRNA biogenesis competes with pre-mRNA splicing. Mol Cell 56:55-66
Funding Open Access funding enabled and organized by Projekt DEAL. Open Access Dieser Artikel wird unter der Creative Commons Namensnennun 4.0 International Lizenz verơffentlicht, welche die Nutzung, Vervielfältigun erlaubt, sofern Sie den/die ursprünglichen Autor(en) und die Quelle ordnungsgemäß nennen, einen Link zur Creative Commons Lizenz beifügen und ngeben, ob Anderungen vorgenommen wurden. Die in diesem Artikel enthaltenen Bilder und sonstiges Drittmaterial unterliegen ebenfalls der genannten Creative Commons Lizenz, sofern sich aus der Abbildungslegende nichts anderes ergibt. Sofern das betreffende Material nicht unter der

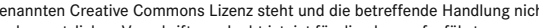
Wererwenture Rechteinhabers einzuholen. Weitere Details zur Lizenz entnehmen Sie bitte der Lizenzinformation auf http://creativecommons org/licenses/by/4.0/deedde.
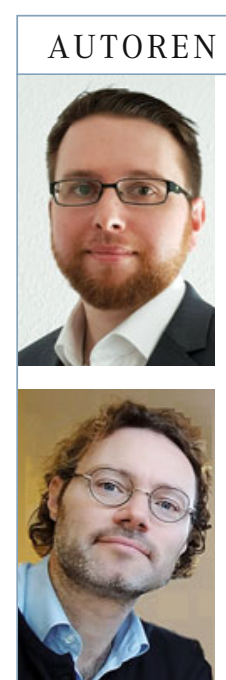

\section{Marcel Boss}

2010-2015 Studium der Biochemie an der Universität Greifswald. 2015-2020 Promotionsstudium in Chemie an der HU Berlin.

Prof. Dr. Christoph Arenz

Institut für Chemie

Humboldt-Universität zu Berlin

Brook-Taylor-Straße 2

D-12489 Berlin

christoph.arenz@chemie.hu-berlin.de

1991-1997 Studium der Chemie an der Universität Bonn. 1998-2000 Promotion in Chemie an der Universität Karlsruhe (TH). 2000-2004 Postdoktorand in Molekularbiologie, Universität Bonn. 2004-2011 Juniorprofessor für Bioorganische Chemie an der HU Berlin. Seit 2012 ordentlicher Professor für Organische Chemie ebendort. 